\title{
Immunoreduction of ocular surface tumours with intralesional interferon alpha-2a
}

\begin{abstract}
Purpose To share our initial experience in the use of intralesional interferon alpha-2a at primary presentation in ocular surface tumours as a method of immunoreduction prior to definitive surgical management.

Methods Case series of patients referred to Sheffield Ocular Oncology Service with rapidly growing ocular surface tumours, treated with intralesional interferon alpha-2a at first presentation prior to definitive surgical management.

Results All three patients, two with conjunctival melanoma and one with ocular surface squamous neoplasia (OSSN) demonstrated immunoreduction of tumour without any adverse side effects.

Conclusions Interferon alpha-2a is effective in conjunctival melanoma and OSSN.

Intralesional interferon at first presentation may be used for immunoreduction prior to definitive surgical management. This may improve surgical and long-term outcomes, improve patient experience, and help meet cancer treatment targets.

Eye (2018) 32, 460-462; doi:10.1038/eye.2017.196; published online 22 September 2017
\end{abstract} UK

Tel: +44 (0)114 271 3829;

Fax: +44 (0)1142713682.

E-mail: ella.kim@doctors.

org.uk

Received: 12 June 2017 Accepted: 2 August 2017

Published online:

22 September 2017

This paper was presented at the International Society of Ocular Oncology (ISOO) biennial meeting, Sydney in March 2017 and was awarded the 'Best Trainee Paper Award'.
SE Kim and SM Salvi

We present our initial experience with the innovative use of intralesional interferon alpha-2a (IFN-alpha-2a) at first clinic visit as a method of immunoreduction prior to definitive surgical management of ocular surface tumours.

\section{Case reports}

Case 1

A 60-year-old female was referred with a 3-month history of a rapidly growing lesion on her left eye. She was clinically diagnosed with a left temporal limbal conjunctival melanoma, and listed for excision, cryotherapy, and amniotic membrane graft. Given the size and rapid growth, she was treated with 3 million international units (MIU) of intralesional IFNalpha-2a on the day to control the disease while awaiting surgery. On the day of surgery (28 days post-injection), the lesion was noted to have reduced in size and vascularity, and had betterdefined margins. She was successfully treated with surgical resection followed by Ruthenium plaque brachytherapy.

\section{Case 2}

A 74-year-old male was referred with a rapidly growing lesion involving the lateral part of the left superior fornix extending onto the bulbar conjunctiva and tarsus. He had been treated 5 years previously for a left temporal limbal conjunctival melanoma. He was clinically diagnosed with a recurrence of conjunctival melanoma and was listed for multi-stage surgical resection. Given the large size and rapid growth, he was treated with 3 MIU intralesional IFN-alpha-2a on the day of diagnosis. On the day of surgery (18 days postinjection), the lesion was noted to have reduced in size and vascularity, with better-defined 

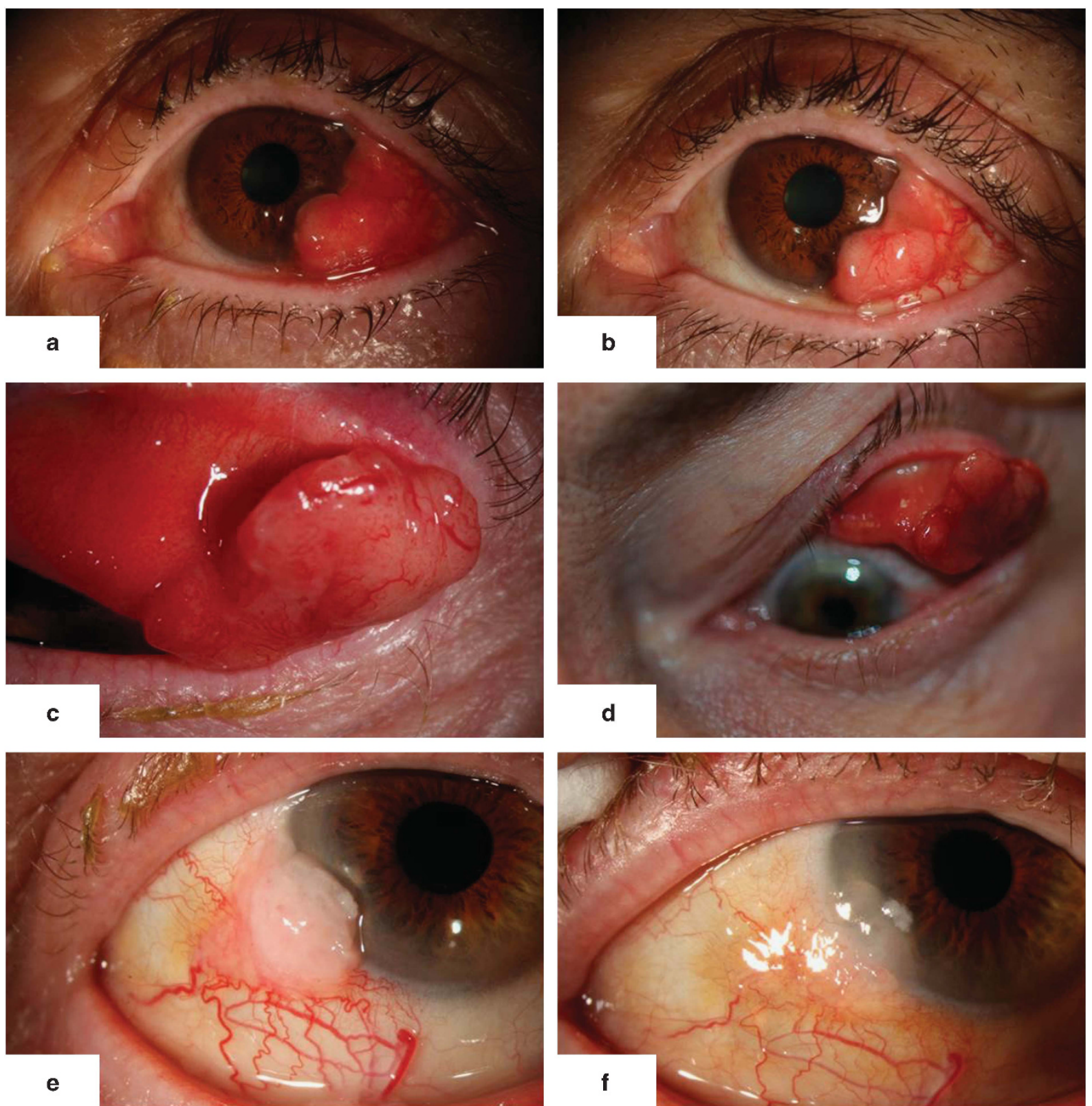

Figure 1 Composite of slit lamp photographs. Case 1: large left temporal limbal conjunctival melanoma at diagnosis (a) and immunoreduction at 28 days following intralesional Interferon alpha-2a injection (b). Case 2: large left superior fornix and tarsal conjunctival melanoma at diagnosis (c) and immunoreduction at 18 days following intralesional Interferon alpha-2a injection (d). Case 3: large temporal limbal conjunctival ocular surface squamous neoplasia at diagnosis (e), and immunoreduction at 28 days following intralesional Interferon alpha-2a injection (f).

margins. He had successful excision of the lesion with clear margins.

\section{Case 3}

A 79-year-old male was referred with a 3-month history of a rapidly growing lesion on the right temporal limbus. He was clinically diagnosed with a conjunctival OSSN and was listed for surgical resection with cryotherapy and amniotic membrane graft.

Given the rapid onset, 3 MIU intralesional IFN-alpha-2a was given on the day of diagnosis. On the day of surgery (28 days post-injection), the lesion was noted to have reduced in size and inflammation. Regression of the disease was also confirmed by histology. (Figure 1). 


\section{Discussion}

Conjunctival melanomas and ocular surface squamous neoplasias (OSSN) have a reported incidence of $0.4^{\text {(ref. 3) }}$ and $0.3-19^{\text {(ref. 4) }}$ per million, respectively. Although rare, they are the most common ocular surface tumours referred to sheffield ocular oncology service. Diagnosis is made clinically at first visit and patients are listed for definitive surgical resection by wide local excision combined with adjuvant cryotherapy to be done within 31 days to meet national cancer treatment targets. These tumours can be large and may grow rapidly while awaiting treatment. Increased size and thickness are associated with worse prognosis, ${ }^{5}$ and can also make surgery more challenging.

We present our initial experience in the use of intralesional IFN-alpha-2a at primary presentation in ocular surface tumours as a method of immunoreduction prior to definitive surgical treatment.

Interferons are glycoproteins secreted by the immune system that exhibit antiviral, antimicrobial, and antineoplastic properties, ${ }^{6}$ thought to be secondary to a combination of antiproliferative, antiangiogenic, and cytotoxic effects. ${ }^{7}$ Interferon alpha-2b has been used in the form of topical drops ${ }^{8}$ and peri-lesionally ${ }^{9}$ to treat OSSN. At Sheffield Ocular Oncology Service, we use IFN-alpha$2 a$ (Roferon-a) rather than $2 b$ (Intron-a) due to ease of availability and cost. We believe this is the first paper reporting the efficacy of intralesional IFN-alpha-2a in ocular tumours.

All tumours in our case series (two conjunctival melanomas and one OSSN) had reduction in size and vascularity (within 18-28 days) following intralesional IFN-alpha-2a injection. In addition, at surgery the tumour margins were noted to be better defined, thus aiding the surgical resection. We believe this will improve prognosis by reducing risk of local recurrence and metastasis.

It has been reported that $64 \%$ of patients experience mental health problems, such as anxiety and depression while waiting for cancer treatment, ${ }^{10}$ and so commencing treatment on the day of diagnosis may improve patient experience. In addition, commencing treatment at diagnosis will also help ocular oncology centres continue to meet cancer treatment targets in spite of increasing number of referrals. ${ }^{11}$

We thus recommend immunoreduction with intralesional interferon at diagnosis in patients with large or rapidly growing ocular surface tumours prior to definitive surgical management.
Summary

What was known before

- Chemoreduction has been used in retinoblastoma and lacrimal gland tumours.

- Topical and peri-lesional interferon alpha-2b is used in treatment of ocular surface squamous neoplasia.

What this study adds

- Interferon alpha-2a is effective in ocular surface tumours (conjunctival melanomas and OSSN).

- Intralesional interferon can be used for immunoreduction of ocular surface tumours prior to definitive surgical management.

- Immunoreduction can improve surgical and long-term outcomes, improve patient experience, and help meet cancer treatment targets.

\section{Conflict of interest}

The authors declare no conflict of interest.

\section{References}

1 Shields CL, De Potter P, Himelstein BP, Shields JA, Meadows AT, Maris JM. Chemoreduction in the initial management of intraocular retinoblastoma. Arch Ophthalmol 1996; 114: 1330-1338.

2 Shields CL, Demirci H, Marr BP, Masheyekhi A, Materin M, Shields JA. Chemoreduction with topical mitomycin $C$ prior to resection of extensive squamous cell carcinoma of the conjunctiva. Arch Ophthalmol 2005; 123: 109-113.

3 McLaughlin CC, Wu XC, Jemal A, Martin HJ, Roche LM, Chen VW. Incidence of noncutaneous melanomas in the US. Cancer 2005; 103: 1000-1007.

4 Sun EC, Fears TR, Goedert JJ. Epidemiology of squamous cell conjunctival cancer. Cancer Epidemiol Biomark Prev 1997; 6: 73-77.

5 Tuomaala S, Kivelä T. Metastatic pattern and survival in disseminated conjunctival melanoma: implications for sentinel lymph node biopsy. Ophthalmology 2004; 111: 816-821.

6 Baron S, Tyring SK, Fleischmann Jr WR, Coppenhaver DH, Niesel DW, Klimpel GR et al. The interferons. Mechanisms of action and clinical applications. JAMA 1991; 266: 1375-1383.

7 Bracarda S, Eggermont AM, Samuelsson J. Redefining the role of interferon in the treatment of malignant diseases. Eur J Cancer 2010; 46: 284-297.

8 Shah SU, Shah SU, Kaliki S, Kim HJ, Lally SE, Shields JA et al. Topical interferon alfa-2b for management of ocular surface squamous neoplasia in 23 cases outcomes based on American joint committee on cancer classification. Arch Ophthalmol 2012; 130: 159-164.

9 Karp CL, Galor A, Chhabra S, Barnes SD, Alfonso EC. Subconjunctival/perilesional recombinant interferon alpha $2 \mathrm{~b}$ for ocular surface squamous neoplasia a 10-year review. Ophthalmology 2010; 117: 2241-2246.

10 Macmillan. Macmillan Cancer Support/YouGov survey of 1020 adults in the UK with a previous cancer diagnosis 2016.

11 Kim SE, Salvi SM. In Ocular Oncology Annual Commissioning for Quality and Innovation (CQUIN) Meeting 2017. 